\title{
A Simplified Power Sizing Method for the Correct Building Integration of Wood Stoves
}

\author{
Martin Thalfeldt ${ }^{1,3, *}$, Anders Skare ${ }^{1}$, Laurent Georges ${ }^{1}$, Øyvind Skreiberg $^{2}$ \\ ${ }^{1}$ Department of Energy and Process Engineering, Norwegian University of Science and Technology, Trondheim, Norway \\ ${ }^{2}$ SINTEF Energy Research, Trondheim, Norway \\ ${ }^{3}$ Department of Civil Engineering and Architecture, Tallinn University of Technology, Tallinn, Estonia
}

\begin{abstract}
Wood stoves are widely used in dwellings for space heating, however transient heat output and relatively large heat emission might cause problems with over-heating in new well-insulated buildings. This paper introduces a simplified power sizing method for the building integration of wood stoves which was compared to dynamic building performance simulations. The analysis showed that on average the simplified method predicted the temperature increase in the living room similarly to dynamic simulations. However, in some cases the difference was up to $60 \%$, which is significant when carried forward to selecting the optimal stove heat capacity. Precise use of the simplified power sizing method requires accurate knowledge of the building structures and effective thermal capacity of the room with the wood stove. Typically, this kind of knowledge is unavailable when selecting a wood stove and the method needs to be developed further. These investigations confirmed that more knowledge of the occupant behaviour and preference on thermal comfort is needed.
\end{abstract}

\section{Introduction}

Wood stoves are widely used and offer a good opportunity to use biomass for space-heating and reduce $\mathrm{CO}_{2}$ emissions. Kipping and Trømborg [1] studied 608 households in Norway and wood stoves were used in more than $90 \%$ of them. Wood stoves are highlyconcentrated heat sources compared to other typical space-heating devices. Their transient heat output may create problems that need to be addressed as buildings are becoming more and more insulated. The dominant challenge is thermal discomfort due to over-heating and vertical temperature stratification (caused by the plume of the stove).

Thermal comfort can be evaluated with building performance simulations (BPS). Georges et al. [2, 3] has conducted such investigations and showed that proper integration of wood stoves in passive houses is possible both in the mild climate of Belgium and cold climate zones of Norway. The use of BPS to evaluate the timevarying operative temperature during the space-heating using a stove has been validated experimentally [4]. Unfortunately, these detailed simulations are not accessible when people (possibly assisted by wood stove dealers) have to select a stove for their home. Therefore, a simple but accurate enough method for selecting the correct wood stove is needed.

This paper proposes a simplified power sizing method for the correct building integration of wood stoves. The main purpose of the study is to validate the method against detailed building performance simulations. The power sizing method is based on temperature increase calculations during a wood stove combustion cycle as a function of building thermal mass and heat losses. This enables to check whether a stove generates overheating or if a stove is powerful enough to provide thermal comfort in cold winter periods. Therefore, the main focus was set on the accuracy of temperature increase predictions. To validate the method, parametric runs were performed using detailed annual simulations of a detached house, which is the dominant building typology in Norway. The simulations were conducted with different insulation level, thermal mass and stove nominal capacity.

\section{Methods}

\subsection{Simplified power sizing method for wood stoves}

Typically, space-heating systems should first and foremost assure a minimum room temperature during the heating period. However, wood stoves are in most buildings supplemented by another automated heating system [5], which is serving that role. Even though a stove can be used to heat the building at a minimum room temperature, this paper rather focuses on a simplified power sizing method for wood stoves that determines only the maximum nominal power $P_{n, \max }(\mathrm{W})$ to avoid overheating in the room during one stove cycle. The simplified method is based on Equation 1 which is a simple energy balance equation that aims at evaluating $P_{n, \max }$.

\footnotetext{
${ }^{*}$ Corresponding author: martin.thalfeldt $@$ taltech.ee
} 


$$
\begin{array}{r}
P_{n, \text { max }} \cdot \beta_{\text {mod }}=U A_{\text {env }} \cdot\left(T_{\text {set }, S H}-T_{\text {out } \text { max }}+\Delta T_{\text {max }}\right)+ \\
U A_{\text {int }} \cdot \Delta T_{\text {max }}+C_{\text {eff,room }} \cdot \frac{\Delta T_{\text {max }}}{t_{\text {cycle }}}
\end{array}
$$

In general, the power limit depends on the power modulation capability $\beta_{\text {mod }}(-)$, the heat losses of the room to outdoors and other rooms of the building, and the ability of the room structures to absorb the heat emitted by the stove. Equation 1 is intuitively divided into three terms. Firstly, the heat losses through the room external envelope constrain the temperature increase $\Delta T(\mathrm{~K})$ depending on the specific heat losses $U A_{\text {env }}(\mathrm{W} / \mathrm{K})$, room heating temperature setpoint $T_{\text {set,SH }}\left({ }^{\circ} \mathrm{C}\right)$ and pivot outdoor temperature $T_{\text {out,max }}\left({ }^{\circ} \mathrm{C}\right)$. The pivot outdoor temperature is the maximum outdoor temperature below which people use the stove. In other words, above $T_{\text {out,max }}$, it is unlikely that people use the stove as the outdoor temperature is too mild.

Secondly, the heat losses to other rooms of the building restrict the temperature increase depending on the specific heat losses through internal structures $U A_{\text {int }}$ $(\mathrm{W} / \mathrm{K})$ and temperature difference between zones $\Delta T$. The heating temperature setpoint in different zones should be taken into account as well as the position of doors as it influences heat losses: doors or other openings increase the heat transfer between zones significantly. In this study, we have assumed that doors are closed and temperature setpoints are equal in all zones. Both assumptions are conservative regarding the assessment of overheating.

The third and final limiter of the temperature increase is the effective thermal capacity of the room $C_{\text {eff,room }}$ $(\mathrm{kWh} / \mathrm{K})$ and the length of the stove cycle $\underline{t}_{\text {cycle }}(\mathrm{h})$. The cycle length influences the total amount of heat emitted by the stove and the effective thermal capacity illustrates the capability of room structures to absorb the heat.

\subsection{The simulation model of the detached house}

The accuracy of the simplified power sizing method for wood stoves was compared using annual detailed simulations of a detached house (Fig. 1). This procedure will be here called the model validation. The floor plans of the two-storey building are presented in Fig. 2. The wood stove and the occupant were located in the living room on the ground floor. The location of the occupant is a necessary input to evaluate the operative temperature (see comment here below).

In this section, the methods for annual simulations are described and the validation procedure is given in Section 2.4. The simulations of the detached house were performed with an alpha version of the well-validated dynamic building performance simulation software IDAICE 5 [6], which is currently under development. The main advantage of this version of the software is its capability of accurately assessing the operative temperature at the location of the occupant as it models accurately radiative heat transfer between surfaces. In fact, the living room geometry has a L-shape and the stove geometry is integrated inside the virtual geometry of the room. The resulting geometry is therefore not convex so that view factors between surfaces should be evaluated numerically $[7,8]$.

The location and climate of Oslo were used for annual simulations. The hourly internal heat gain profiles of occupants, equipment and lighting were taken from ISO 17772-1 [9] and are given in Fig. 3. Balanced heat recovery ventilation with a total air flow rate of about 208 $\mathrm{m}^{3} / \mathrm{h}$ was used, which complies with the Norwegian national requirements [10]. The cascade ventilation supplies air to the living room and bedrooms, while extracts from the kitchen, bathrooms, laundry room and staircase.

Stoves with nominal capacity $P_{n}$ between 3 and $12 \mathrm{~kW}$ and total amount of heat emitted from the stove over one cycle (i.e. the batch load) ranging from 7.5 to 30 $\mathrm{kWh} /$ cycle were used in the simulations. Fig. 4 illustrates the heat emission profiles of each stove. These profiles were obtained using a semi-empirical model of wood stoves called FuelSim-Transient, developed by Skreiberg [11]. It models the combustion and heat transfer physics inside the stove.

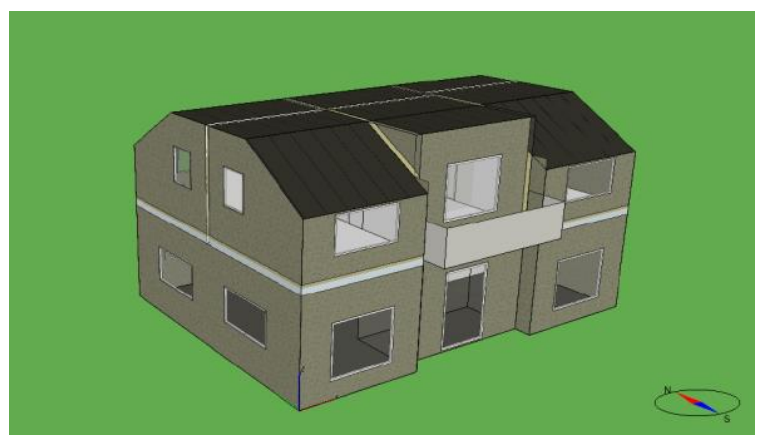

Fig. 1. 3D view of the virtual geometry of the detached house.

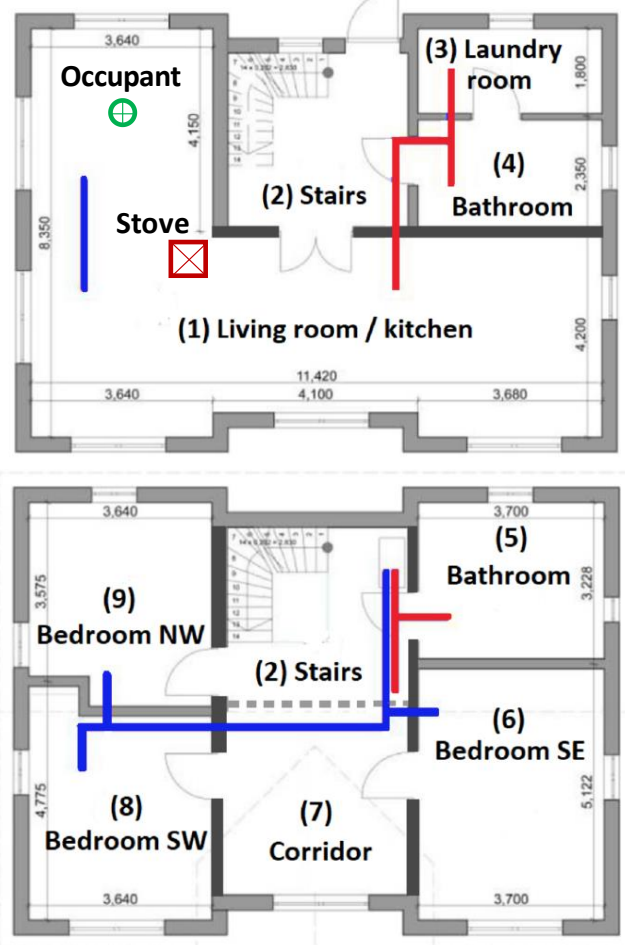

Fig. 2. Ground (top) and $1^{\text {st }}$ floor (bottom) plans of the detached house with the locations of the stove, occupant and mechanical ventilation supply (blue) and extract (red) air ducts. 


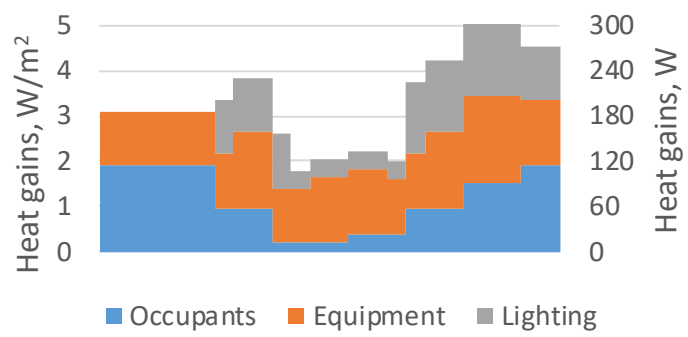

Fig. 3. The internal (sensible) heat gains of one 24-hour day from occupants, equipment and electrical lighting in the living room.

In IDA-ICE, these heat emission profiles were given as an input to the stove model. Given realistic stove dimensions for each nominal capacity $\left(P_{n}\right)$, the resulting stove surface temperature is computed dynamically by IDA ICE for each time step.

The following rule-based control algorithm for stove operation was implemented in IDA-ICE:

- A stove cycle was started when the operative temperature in the living room was $20{ }^{\circ} \mathrm{C}$ (or below) and during occupancy. The occupancy time was defined between 07:00-10:00 and 19:00-22:00 during weekdays and between 07:00-22:00 during weekends.

- The total heat emission of the stove, meaning convective power and longwave radiation, was imposed as emitted power from the stove as a function of time from the start of the cycle according to profiles provided in Fig. 4.

\subsection{The construction of the detached house}

The study included various insulation levels and construction modes (CM), see Table 1 Table 2, respectively. The construction modes influence the thermal capacity of the building. The insulation level ranged from passive house $(\mathrm{PH})$ level to the Norwegian national requirements from 1987 (TEK87). The specific heat losses of cases TEK97 and TEK 87 are significantly higher due to no ventilation heat recovery and thus the supply air was not pre-heated before being supplied to the zones.

The specific heat losses through internal constructions of the living room depended only on the construction mode (see Table 2). The effective thermal capacities were calculated according to EN ISO 52016-1:2017 [12] assuming that either $10 \mathrm{~cm}\left(C_{\text {eff, } 10}\right)$ or $2 \mathrm{~cm}\left(C_{\text {eff, }, 2}\right)$ of the constructions thermal mass are activated during one stove cycle. The effective thermal masses presented in this section were compared to values derived from dynamic simulations. The effective thermal capacity calculations are described in the next section. The calculations of the specific heat losses and effective thermal capacity have been described in detail in Ref. [13].
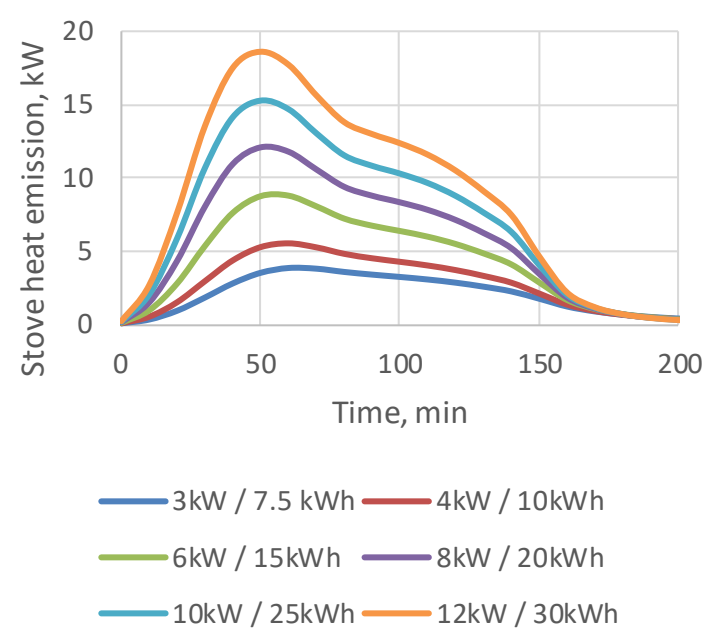

Fig. 4. The heat emission profiles of all wood stoves as a function of stove nominal capacity and the batch load.

Table 1. The specific heat loss through living room exterior envelope $\left(U A_{\text {env }}\right)$ as function of thermal insulation level.

\begin{tabular}{|c|c|c|}
\hline Thermal insulation level & $\mathrm{UA}_{\mathrm{env}}, \mathrm{W} / \mathrm{K}$ & $\begin{array}{c}\text { Stove } P_{n} \text { range, } \\
\mathrm{kW}\end{array}$ \\
\hline Passive house (PH) [14] & 31.5 & $3,4,6$ \\
\hline TEK10 [10] & 49.6 & $3,4,6$ \\
\hline TEK07 [15] & 56.1 & $4,6,8$ \\
\hline TEK97 [16] & 91.3 & $4,6,8,10$ \\
\hline TEK87 [17] & 118.0 & $6,8,10,12$ \\
\hline
\end{tabular}

Table 2. The calculated specific heat loss through internal constructions $\left(U A_{\text {int }}\right)$ and thermal capacity $(C)$ of living rooms depending on the construction mode $(\mathrm{CM})$ and the thickness of effective construction depth $10 \mathrm{~cm}\left(C_{\text {eff, } 10}\right)$ or $2 \mathrm{~cm}\left(C_{\text {eff, }, 2}\right)$.

\begin{tabular}{|c|c|c|c|c|}
\hline $\begin{array}{l}\text { Construction } \\
\text { mode }\end{array}$ & Description & $\begin{array}{l}\mathrm{UA}_{\text {int }}, \\
\mathrm{W} / \mathrm{K}\end{array}$ & $\begin{array}{l}\mathrm{C}_{\text {eff, } 10,} \\
\mathrm{kWh} / \mathrm{K}\end{array}$ & $\begin{array}{c}\mathrm{C}_{\text {eff, }, 2} \\
\mathrm{kWh} / \mathrm{K}\end{array}$ \\
\hline CM1 & $\begin{array}{c}\text { Masonry } \\
\text { heavy }\end{array}$ & 187.0 & 7.94 & 1.48 \\
\hline CM2 & $\begin{array}{l}\text { Mixed wood- } \\
\text { masonry }\end{array}$ & 157.6 & 5.58 & 1.32 \\
\hline CM3 & $\begin{array}{c}\text { Wooden } \\
\text { heavy }\end{array}$ & 76.5 & 3.45 & 1.07 \\
\hline CM4 & $\begin{array}{c}\text { Masonry } \\
\text { light }\end{array}$ & 41.8 & 2.57 & 0.99 \\
\hline CM5 & Wooden light & 25.1 & 1.77 & 1.02 \\
\hline
\end{tabular}

\subsection{Validation procedure of the simplified power sizing method}

The validation procedure of the simplified power sizing method was conducted to assess its accuracy when predicting the temperature increase during a stove cycle. It was done in three steps.

Firstly, the operative temperature increase during one stove cycle $(\Delta T)$ was plotted as a function of daily average 
outdoor temperature $T_{\text {out }}\left({ }^{\circ} \mathrm{C}\right)$ based on annual dynamic simulations. Based on the plotted values, Equation 2 was derived, where constant $a(-)$ illustrates the slope of the linear function. Constant $b\left({ }^{\circ} \mathrm{C}\right)$ illustrates the temperature increase during one cycle at outdoor temperature $0{ }^{\circ} \mathrm{C}$. Constants $a$ and $b$ varied for each studied case.

$$
\Delta T=a \cdot T_{\text {out }}+b
$$

Secondly, effective thermal mass $C_{\text {eff }}$ was calculated based on daily simulations of the living room with adiabatic internal construction, at outdoor temperature $0{ }^{\circ} \mathrm{C}$ and one stove cycle. The effective thermal mass was calculated with Equation 3 based on the modelled operative temperature increase and the stove nominal power $P_{n}$ and stove cycle length $t_{c y c l e}$. The latter two were known and imposed to the stove model in IDA-ICE. All combinations of insulation levels, construction modes and stove powers were included in the first step and were analysed.

$$
C_{e f f} \sim \frac{P_{n} \cdot t_{c y c l e}}{\Delta T}
$$

Thirdly, for calculating the simplified temperature increase, Equation 4 was derived from Equation 1. In this study, the stove cycle length $t_{c y c l e}$ was $2.5 \mathrm{~h}$, the modulation capability $\beta_{\bmod }$ was 1 , meaning the stove operated at nominal power. ISO 17772-1 [9] gives a temperature range of $20.0-25.0^{\circ} \mathrm{C}$ for indoor climate class II. Therefore, $T_{\text {set, } S H}$ can be assumed to be $20^{\circ} \mathrm{C}$. The other parameters varied from case to case and are given in Table 1 Table 2, and the effective thermal mass presented in the previous paragraph is used.

$$
\Delta T=\frac{t_{\text {cycle }} \cdot\left[\beta_{\text {mod }} \cdot P_{n}-U A_{e n v} \cdot\left(T_{\text {set }, S H}-T_{\text {out }}\right)\right]}{C_{e f f}+t_{c y c l e} \cdot\left(U A_{\text {env }}+U A_{\text {int }}\right)}
$$

The temperature increases calculated based on Equations 2 and 4 gave different results in several test cases. To analyse this, the temperature increase of the simplified method was broken down into three components: the temperature increase from thermal mass $\left(\Delta T_{\text {Ceff, }}, \mathrm{K}\right)$, heat losses through external envelope $\left(\Delta T_{\text {env }}\right.$, $\mathrm{K})$ and internal structures $\left(\Delta T_{i n t}, \mathrm{~K}\right)$, where $\Delta T_{e n v}$ and $\Delta T_{i n \mathrm{t}}$ typically have negative values:

$$
\Delta T=\Delta T_{C_{e f f}}+\Delta T_{e n v}+\Delta T_{i n t}
$$

If the structures of the room are assumed to be adiabatic $\left(U A_{\text {env }}=0, U A_{\text {int }}=0\right)$, then the only room parameter limiting the temperature increase is thermal mass. Then, Equation 4 takes the following form enabling to calculate $\Delta T_{\text {Ceff }}$.

$$
\Delta T_{C_{e f f}}=\frac{\beta_{m o d} \cdot P_{n} \cdot t_{c y c l e}}{C_{e f f}}
$$

To calculate $\Delta T_{\text {env }}$ and $\Delta T_{\text {int }}$, it was assumed that their ratio is equal to the ratio of heat losses through the external envelope and internal structures respectively:

$$
\frac{\Delta T_{\text {env }}}{\Delta T_{\text {int }}}=\frac{U A_{e n v} \cdot\left(T_{\text {set }, S H}-T_{o u t}+\Delta T\right)}{U A_{\text {int }} \cdot \Delta T}
$$

The Equation 8 to calculate $\Delta T_{e n v}$ was derived from Equations 5 and 7:

$$
\Delta T_{\text {env }}=\frac{\left(\Delta T_{C_{e f f}}-\Delta T\right) \cdot U A_{e n v} \cdot\left(T_{\text {set }, S H}-T_{\text {out }}+\Delta T\right)}{U A_{\text {int }} \cdot \Delta T+U A_{e n v} \cdot\left(T_{\text {set }, S H}-T_{\text {out }}+\Delta T\right)}
$$

The Equation 9 to calculate $\Delta T_{e n v}$ was derived from Equation 5:

$$
\Delta T_{i n t}=\Delta T_{C_{e f f}}-\Delta T_{e n v}-\Delta T
$$

\section{Results}

\subsection{Effective thermal capacity}

The effective thermal capacity $\left(C_{e f f}\right)$ calculated based on dynamic simulations depended significantly on both the construction mode and insulation level. Fig. 5 presents the effective thermal capacities of construction modes CM1, CM3 and CM5 with all insulation levels and stove nominal powers. The stove nominal power did not have remarkable impact on effective thermal capacity. Therefore, many data points are not distinguishable.

Fig. 5 also includes the thermal capacity calculated assuming that the inner $2 \mathrm{~cm}$ of the living room structures are activated $\left(C_{e f f, 2}\right)$. The figure shows that effective thermal capacity varied significantly between cases with the same construction mode. Therefore, assessing the effective thermal mass using constant thickness for the activated thermal mass should not be done in analyses with wood stoves. The impact of effective thermal mass on the simplified calculation results is especially large for well-insulated buildings, where the temperature increase is supposed to be mainly affected by thermal mass.

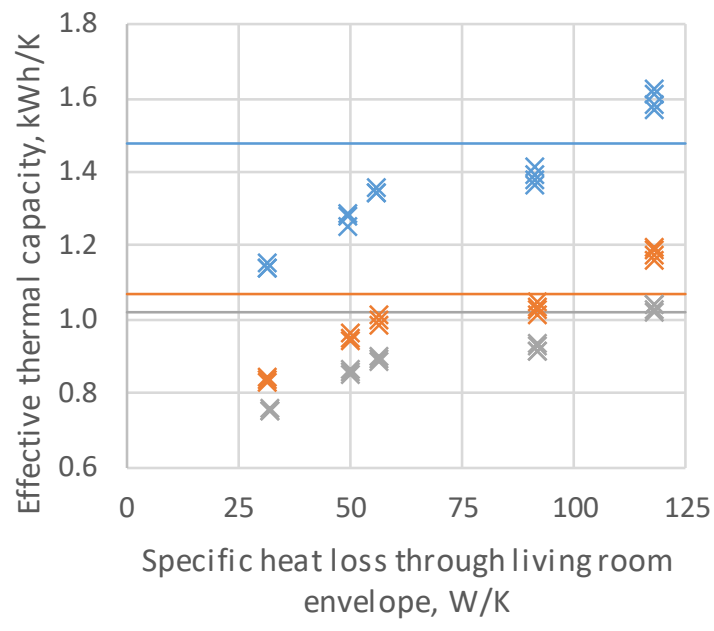

$\times \mathrm{CM} 1 \times \mathrm{CM} 3 \times \mathrm{CM} 5$

Fig. 5. The effective thermal capacity of cases with construction modes CM1, CM3 and CM5 for all insulation levels (horizontal lines represent $\mathrm{C}_{\text {eff,2 }}$ from Table 1). 


\subsection{Operative temperature increase during a stove cycle}

The annual simulations showed that operative temperature increase had a linear dependence of outdoor temperature. Fig. 6 compares the results of annual simulations and the temperature increase calculated with the simplified method. For sake of conciseness, the cases with a $6 \mathrm{~kW}$ stove, highest and lowest thermal mass (CM1 and CM5) and insulation levels (PH and TEK87) are presented in this section. The simplified method applied to the passive house resulted to temperature increases that are more dependent on the outdoor temperature compared to dynamic simulations (see Fig. 6a,c). This is especially clear for the passive house case with highest thermal mass (CM1), where temperature increase was almost constant in dynamic simulations regardless of outdoor temperature. In addition, in its current version, the simplified method did not take into account internal heat gains. The daily internal heat gains in the living room vary between 100 and $300 \mathrm{~W}$, which should result in a temperature increase of a few degrees.
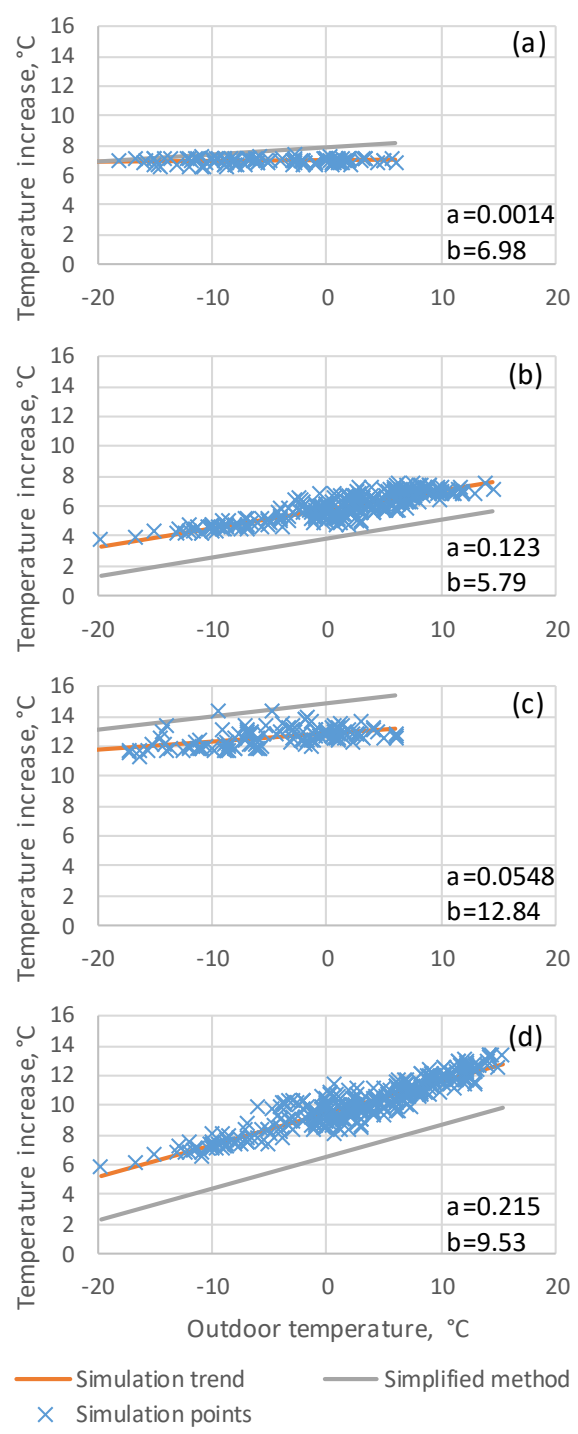

Fig. 6. The temperature increase based on simplified method and simulations for cases using a $6 \mathrm{~kW}$ stove and the following insulation levels and construction modes - PH, CM1 (a); TEK87, CM1 (b); PH, CM5 (c); TEK87, CM5 (d).
The dependence of temperature increase of TEK 87 cases (see Fig. 6b,d) was similar for both the simplified method and dynamic simulations. There was an offset of $2-3 \mathrm{~K}$ between the methods with the simplified method resulting in lower temperature increase, which is in the same range as the temperature increase caused by the internal gains. Therefore, the correspondence between the simplified method and dynamic simulations was good for the presented TEK87 cases. However, the simplified method was not accurate in case of well-insulated buildings while these buildings present the biggest challenge regarding the integration of wood stoves. Based on simulations, the pivot outdoor temperature, i.e. the temperature above which the stove was not operated, was approximately 5 and $15{ }^{\circ} \mathrm{C}$ for passive house and TEK 87 cases respectively.

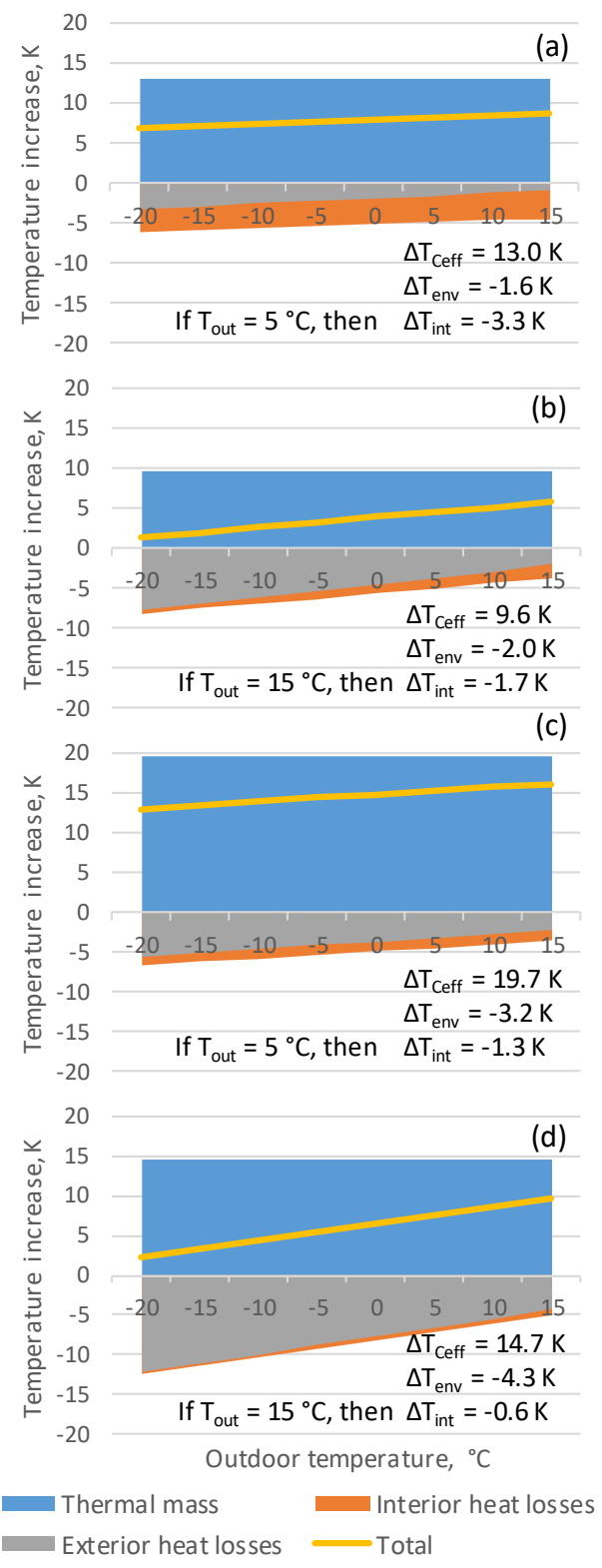

Fig. 7. The temperature increase components based on simplified method for cases with $6 \mathrm{~kW}$ stove and the following insulation levels and construction modes - PH, CM1 (a); TEK87, CM1 (b); PH, CM5 (c); TEK87, CM5 (d). 
In Fig. 7, the temperature increase calculated with the simplified method has been broken down into components $\Delta T_{\text {Ceff, }} \Delta T_{\text {env }}$ and $\Delta T_{\text {int }}$. The presented cases are identical to Fig. 6 . The components regarding heat losses have negative values. The figure also highlights the values of the components at pivot outdoor temperatures (i.e. $5^{\circ} \mathrm{C}$ or $15^{\circ} \mathrm{C}$ depending on the insulation level). The effective thermal mass had the largest influence on the temperature increase for all cases, especially with the passive house insulation level. Therefore, this parameter is critical.

The passive house with highest thermal mass (Fig. 7a) was the only one where the heat losses through internal structures had significant impact on temperature increase. Whereas, at pivot outdoor temperature $5^{\circ} \mathrm{C}$, the impact of heat losses through the external envelope was significantly lower: -1.6 and $-3.3 \mathrm{~K}$, respectively. In other cases, the impact of heat losses through the external envelope was larger compared to heat losses through internal structures.

Fig. 8 illustrates how the simplified calculation method performed in comparison to the dynamic detailed simulations for all cases. The figure presents the temperature increases of each studied case at outdoor temperature $5{ }^{\circ} \mathrm{C}$, which was the lowest pivot outdoor temperature of all studied cases. On average, the difference between the results of both methods was not large, with the dynamic simulations giving slightly larger temperature increases. However, from case to case, the differences could be significant between both methods. For example, for cases where the simplified method resulted to an acceptable temperature increase of $5 \mathrm{~K}$, the valued computed using the detailed simulations could be up to $3 \mathrm{~K}$ higher, i.e. a total of $8 \mathrm{~K}$ increase. In this case, the simplified method would allow selecting a wood stove with $60 \%$ higher nominal capacity in comparison to detailed dynamic simulation based selection.

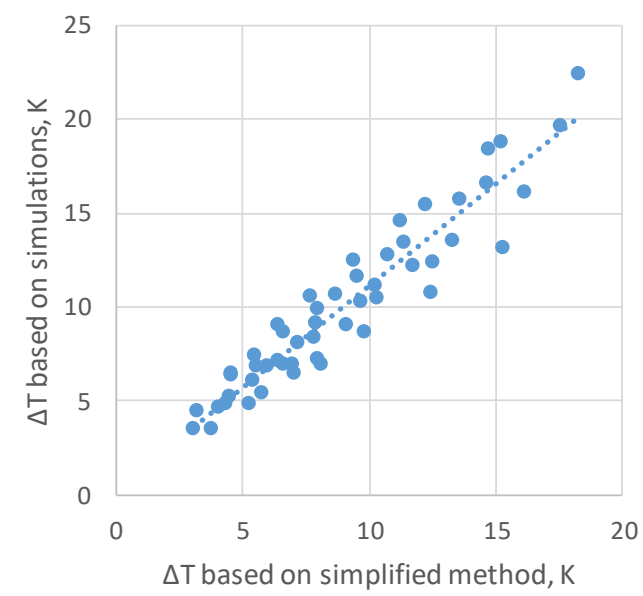

Fig. 8. The simulation based temperature increase in comparison with the temperature increase calculated with the simplified method at outdoor temperature $5{ }^{\circ} \mathrm{C}$.

\section{Discussion}

The presented simplified power sizing method for wood stoves can be used assuming that the following information is known:

- the stove batch size and heat emission profile

- the thermal properties of the room, where the stove is located (i.e. the thermal transmittance and effective thermal capacity)

- the occupants' acceptance criteria for thermal comfort in buildings heated by wood stoves

In this study, several assumptions regarding these aspects were made to assess the accuracy of the simplified method. The assumptions about occupant behaviour and preferences had a strong impact on the results of the annual simulations.

Firstly, the stove operation was controlled only according to the operative temperature in the living room and the time of the day. During the preparation of this study, spontaneous conversations with people who have wood stoves in the houses were held. They pointed out that outdoor conditions (e.g. temperature and solar radiation) or other behavioural patterns might have significant impact on the period when the stoves are operated.

Secondly, the same heat emission profiles of stoves were assumed each time the stove was operated. It is probable that people adjust the amount of wood they use per batch depending on the conditions. This eventually influences the heat emission profiles.

Thirdly, in this study the temperature increase of $5 \mathrm{~K}$ during a stove cycle was used as thermal comfort criterion based on the temperature range given in ISO 17772-1 [9]. This range is typically applied in buildings with more conventional heating systems that have the sole purpose of achieving the room heating temperature setpoint. However, wood stoves are often used to create a feeling of coziness. In the vicinity of the stove, high thermal radiation might be acceptable or desirable. In addition, the temperature increase caused by the stove is self-induced i.e. people themselves light the stove. Thus they might find a temperature increase larger than $5 \mathrm{~K}$ acceptable. For example, in the field measurements of Carvalho et al. [18] in Denmark, they recorded room temperature fluctuations between 20 and $30{ }^{\circ} \mathrm{C}$ almost every day during a 3 week period in February within a low carbon dwelling with a wood stove.

Another criterion for evaluate thermal comfort is the duration of the periods where the operative temperature is outside the acceptable range. The simplified stove control algorithm did not enable using this criterion. Comparison of cases have shown some illogical results e.g. some cases had up to 900 stove cycles annually [13]. Also, the batch sizes were constant throughout the year, which is not an accurate depiction of the real situation.

The operative temperature was used to control the stoves and assess the temperature increase in dynamic simulations. The simulation model took into account thermal radiation from the zone surfaces including the stove surfaces. The temperature of the stove fluctuates remarkably during operation thus having effect on the 
operative temperature increase during one stove cycle. This effect is not taken into account by the simplified method and the significance of this simplification needs to be studied in detail.

Another possible limitation of the simplified power sizing method for wood stoves is lack of information regarding the building thermal properties. In this study, thorough investigation of the building structures was required to achieve accurate results. However, in real life, wood stoves are typically selected by the best knowledge of the sales person and the building owner. This is probably insufficient to assess the effective thermal mass and heat losses accurately enough. Consequently, further investigations are needed to determine the building thermal properties enough accurately with a limited amount of information about a specific building.

This study is the first step towards developing a robust and reliable simplified power sizing method for the building integration of wood stoves. The aforementioned simplifications and assumptions must be addressed in the future work. Field investigations are needed to illustrate occupant behaviour regarding the stove operation, e.g. when are the stoves operated and how do people adjust the batch sizes and power modulation depending on weather, indoor temperature (or other physical parameters).

\section{Conclusions}

This paper introduced a simplified power sizing method for the proper building integration of wood stoves. The main purpose of this study is to compare the method against detailed annual building performance simulations of a detached house located in Oslo, Norway. The accuracy of the simplified method mainly depends on the correct assessment of effective thermal capacity of the room where the stove is placed. Dynamic simulations revealed that this effective thermal capacity depends on both the construction mode of the building and insulation level. Simple but accurate methods to determine the effective thermal capacity of a building should complement the present simplified method.

The identified effective thermal mass was used in the simplified method to calculate the temperature increase during one stove cycle. Analysis showed that in case of passive houses, the simplified method slightly overestimated the impact of heat losses on temperature increase. With lower insulation levels, the simplified method under-estimated the temperature increase in the living room. However, the simplified method did not take into account internal heat gains while they were included in the simulations. The influence of internal gains could be included in the simplified method.

On average, the temperature increases evaluated using the simplified method corresponded well with the detailed dynamic simulations. However, in some test cases, the difference between the calculated temperature increase would lead to the selection of a stove with up to $60 \%$ difference in nominal power. Therefore, this method for power sizing must be developed further. In addition, more knowledge is required regarding the occupant behaviour in buildings heated using wood stoves, including their preferences in terms of thermal comfort.

The authors acknowledge the financial support by the Research Council of Norway and a number of industrial partners through the research project WoodCFD ("Clean and efficient wood stoves through improved batch combustion models and CFD modelling approaches", 243752/E20).

\section{References}

1. A. Kipping and E. Trømborg, Energy 93, 655-671 (2015).

2. L. Georges, Ø. Skreiberg, and V. Novakovic, Energy Build. 59, 203-213 (2013).

3. L. Georges, Ø. Skreiberg, and V. Novakovic, Energy Build. 72, 87-95 (2014).

4. L. Georges and Ø. Skreiberg, J. Build. Perform. Simul. 9, 663-679 (2016).

5. M. Wöhler et al., Appl. Energy 169, 240-249 (2016).

6. EQUA, 2014. [Online]. Available: http://www.equasolutions.co.uk/en/software/idaice.

7. L. Eriksson et al., Proceedings of the First Building Simulation and Optimization Conference, 2012, 149-156.

8. L. Georges et al., Build. Environ. 149, 169-181 (2019).

9. ISO 17772-1 (2017).

10. Ø. Skreiberg, Fuelsim-Transient: A Mass, Volume and Energy Balance Spreadsheet for Batch Combustion Applications, NTNU, Trondheim, 2002.

11. EN ISO 52016-1:2017 (2017).

12. A. Skare, Validation of a method to select the optimal nominal power of a wood stove in residential buildings, NTNU (2018).

13. NS3700:2013 (2013).

14. Forskrift om teknisk krav til byggverk (Byggetknisk forskrift TEK10) (2010).

15. Tekniske forskrifter til plan- og bygningsloven 2007 (TEK07) (2007).

16. Ren veiledning til teknisk forskrift til plan- og bygningsloven 1997 (TEK97) (1997).

17. Byggeforskrift 1987 (TEK87) (1985).

18. R. L. Carvalho et al., Energy Build. 59, 244-251 (2013). 